\title{
Silent innovation: corporate strategizing in early nanotechnology evolution
}

\section{Andersen, Maj Munch}

Published in:

Journal of Technology Transfer

Link to article, DOI:

10.1007/s10961-011-9215-x

Publication date:

2011

Document Version

Publisher's PDF, also known as Version of record

Link back to DTU Orbit

Citation $(A P A)$ :

Andersen, M. M. (2011). Silent innovation: corporate strategizing in early nanotechnology evolution. Journal of Technology Transfer, 36(6), 680-696. https://doi.org/10.1007/s10961-011-9215-x

\section{General rights}

Copyright and moral rights for the publications made accessible in the public portal are retained by the authors and/or other copyright owners and it is a condition of accessing publications that users recognise and abide by the legal requirements associated with these rights.

- Users may download and print one copy of any publication from the public portal for the purpose of private study or research.

- You may not further distribute the material or use it for any profit-making activity or commercial gain

- You may freely distribute the URL identifying the publication in the public portal

If you believe that this document breaches copyright please contact us providing details, and we will remove access to the work immediately and investigate your claim. 


\title{
Silent innovation: corporate strategizing in early nanotechnology evolution
}

\author{
Maj Munch Andersen
}

Published online: 29 March 2011

(C) Springer Science+Business Media, LLC 2011

\begin{abstract}
Nanotechnology offers a rare opportunity to study the early evolution of a new generic technology in real time. This paper suggests focusing more on the market formation side, rather than technology generation, when seeking to explain technology evolution. Applying an evolutionary capabilities perspective, the paper examines how firms organize innovation in the early embryonic stages of a technology and how the market as a selective device undergoes qualitative change as part of economic evolution. The traditional Danish window chain is used as a case. A model of nanotechnology evolution is proposed which suggests that nanotechnology commercialization is significantly driven by small and medium-sized firms based on their internal knowhow, with larger firms as important suppliers of know how. These smaller firms are adept at addressing social needs which appear to be key factors in the nano-commercialization process. A taxonomy of nine enterprise strategies for entry into nanotechnology is suggested. The paper identifies a marked shift in marketing strategizing among the nanotechnology innovative companies, from being "loud" around the turn of the millennium to becoming increasingly "silent" at the present time, illustrating the unconsolidated stage of the current nanotechnology market.
\end{abstract}

Keywords Nanotechnology - Corporate strategy · Evolutionary economics · Evolutionary capabilities · Technology evolution · Construction · Windows · Eco-innovation · Green nanotechnology

JEL Classification $\mathrm{L} 11 \cdot \mathrm{L} 22 \cdot \mathrm{L} 61 \cdot \mathrm{L} 74$

\section{Introduction}

Nanotechnology —although at a very infant stage of development-is associated with grand promises to become an important driver of global economic and social development

M. M. Andersen ( $\square)$

DTU Management, Technical University of Denmark, 2800 Kgs. Lyngby, Denmark

e-mail: mmua@man.dtu.dk 
(Royal Society 2004; Nanoforum 2004; Aitken et al. 2006; NSET 2009). It is a priority area in most countries, attracting huge investments globally (Lux Research 2007; NSET 2009). The development of nanotechnology offers a rare opportunity to study the early evolution of a new technology, possibly a technological revolution, in real time. Yet, little is known about the innovation dynamics of such early innovation stages. Nanotechnology is often defined as a "general purpose technology" by innovation researchers-a generic technology with enabling properties and pervasive impacts throughout the economy. It is anticipated that the future economic impacts of nanotechnology will be considerable (Bozeman et al. 2007; Youtie et al. 2007; Mangematin and Rieu 2009). However, there is uncertainty as to how and when nanoscience will materialize into a distinct technology or economic sector (Delemarle 2009; Laredo et al. 2010).

Most innovation economic research into nanotechnology focuses on analyzing the time scales and innovation conditions in different phases of nanotechnology development (e.g. Rothaermel and Thursby 2007; Bonaccorsi and Thoma 2008; Shapira and Youtie 2008; Mangematin and Rieu 2009; Delemarle 2009; Mowery 2010; Islam and Miyazaki 2010). This research is dominated by patent and bibliometric studies that focus on the input side (knowledge and technology generation) of the innovation process. On the other hand, the output side (commercialization and market formation aspects) is less well investigated (Shapira et al. 2010).

This paper seeks to inquire on the market formation side about the processes of innovation in nanotechnology. Applying an evolutionary capabilities perspective, it posits that valuable insights into the commercialization dynamics of embryonic innovation may be gained by looking into corporate strategizing among firms in supply chains oriented towards an emerging frontier technology. The analysis seeks to capture how interdependent but heterogeneous firms at different places in a supply chain respond to new technologically-driven profit opportunities.

The construction sector has been chosen as the case, contributing to the limited research available on the role of traditional industries in nanotechnology development. A qualitative study is undertaken of how nanotechnologies enter into the window supply chain in the Danish market. The paper analyses both the strategies of firm entry along the nano-enabled window chain and the emergence of nanotechnology as a criterion in market selection. The empirical analysis focuses on two middle components of the window value chain: the core producers of glass and windows. The paper investigates the proposition that the hype is a distinct feature of nanotechnology that affects market formation.

The paper proposes a model of nanotechnology evolution, arguing that nanotechnology commercialization is driven by small and medium sized firms based on their internal knowhow and by larger firms as important suppliers of knowhow. Smaller firms seem to be adept at sensing and addressing needs, which appear as key factors in the nanotechnology commercialization process. A taxonomy of nanotechnology business strategizing is elaborated, and there is discussion of the observed "silent" nature of nanotechnology innovation.

The structure of the paper is as follows. The next section discusses theoretical considerations and hypotheses, including two current models of nanotechnology development. A third model (Nano III) is proposed. The third section introduces the window chain and the nanotechnology-active companies in the chain. In Sect. 4, the main empirical analysis is presented. This is followed by Sects. 5 and 6, which respectively discuss nanotechnology entry strategizing and review the Nano III evolution model. Concluding comments are offered in Sect. 7. 


\section{Models of nanotechnology evolution}

According to theories of economic organization, a firm's capabilities are the most significant factors in determining what will be done by the firm or the market (Penrose 1959; Richardson 1972). For generic and enabling technologies such as nanotechnology, this raises the research question of how different firms organize their innovation in the early embryonic stages when uncertainties are high as to the economic impacts and future trajectories of the technology. Potentially a wide spectrum of firms may benefit from a new generic technology, but who will be the early producers and users?

Inspired by analyses of industry cycles and dominant designs (Utterback and Abernathy 1975; Tushman and Anderson 1986), a related question is whether nanotechnology evolution will follow similar development models as other general purpose technologies such as biotechnology and information and communications technologies (ICT) (Rothaermel and Thursby 2007; Mangematin and Rieu 2009; Delemarle 2009; Shapira et al. 2010; Mowery 2010). These earlier general purpose technologies exhibited different characteristics and were accompanied by different institutional frameworks. In ICT, emerging in the $1970 \mathrm{~s}$, innovative activities quickly centered around verticallyintegrated firms in the evolved industry (the computer industry and wider electronics sector) associated with the emergence of "modular architectures" and stable interfaces with technological subsystems (Mowery 2010). On the other hand, in biotechnology, emerging in the $1980 \mathrm{~s}$, start-up firms played a catalytic role in initial developments, being important in linking up the new science base to incumbents firms (Laredo et al. 2010).

The emergence of nanotechnology, from the $1990 \mathrm{~s}$ onwards, seems to follow a somewhat different pattern, although there is some disagreement among innovation researchers as to the observed pattern so far. Contrasting models can be discerned. A first model (Model I), as represented by Laredo et al. (2010) and in part by Shapira et al. (2010), suggests that nanotechnology evolution is dominated by large (multinational) companies, underwritten by R\&D and patent development, and focused on markets. While Shapira et al. (2010) also argue that small firms play an important role for nanotechnology commercialization, they conclude that countries with more multinational firms, global start-ups and global research centers are more likely to shift from discovery to commercial applications in nanotechnology.

A second model (Model II) is represented by Mowery (2010). He argues that the organization of nanotechnology resembles that of biotechnology, with universities and their spin offs playing prominent roles. In Model II, science-based technological advances and patenting, aided by patent-friendly environments found since the $1990 \mathrm{~s}$, also are central.

Expectations of a grand nanotechnology revolution seem to be shared by both types of innovation observers. They each view nanotechnology as a new "wave" or megatrend with expected widespread effects on economic and social development (Mowery 2010; Laredo et al. 2010). However, these researchers also observe that nanotechnology commercialization is considerably slower than expected, despite continuous impressive public funding and massive growth rates in scientific publications globally. Patent activities and downstream applications remain somewhat limited, (Laredo et al. 2010; Shapira et al. 2010). Explanations for the slow rate of nanotechnology commercialization are lacking so far. 


\subsection{A third model of nanotechnology development}

In this paper, a third model (Model III) of nanotechnology evolution is proposed which suggests nanotechnology commercialization is driven especially by small and medium sized firms based on their internal knowhow, with larger firms as important suppliers of knowledge. This model is explored through in-depth case studies. In contrast to the patent and bibliometric methods used in several of the studies mentioned above, a case study approach is especially adept at identifying internal and supply-chain knowledge relationships. The case studies show that firms engaged in Model III strategies are adept at identifying social needs and addressing these through nanotechnology commercialization.

Model III builds on evolutionary capabilities theory, adopting a strong systems perspective on nanotechnology evolution. Specifically, the analytical approach draws on the framework developed by Langlois and Robertson (1995) and Langlois (1992, 2002, 2003) which links micro-foundations (organizational and capability parameters) with aggregate market and institutional developments. The three pillars of this framework are: ${ }^{1}$

- The distribution of existing capabilities in firm and market Are existing capabilities distributed widely or contained primarily within the boundaries of large firms?

- The systemic/autonomous nature of the economic change Does the seizing of new profit opportunities require systemic reorganization of capabilities, including the learning of new capabilities, or can change proceed in an autonomous way?

- The level of market development To what extent can required capabilities be tapped readily from the market, and to what extent must they be created from scratch? To what extent are relevant market-supporting institutions in place?

In the following analysis, a major emphasis is placed on the third pillar, though probing how the early nanotechnology market evolves. Key questions posed include: How do new nanotechnology selection properties and market-supporting institutions evolve? Which firms construct the early market and what "dynamic transaction costs" are involved? (See also Langlois 1992). ${ }^{2}$

It is also argued in the paper that nanotechnology commercialization is considerably influenced by hype - the advancement of exaggerated claims about the technology and its potential impacts. Nanotechnology is associated with distinctive forms of hype, related to its technological nature: the ability to manipulate nature at the fundamental atomic level leads to fantasizing and speculations both of grand opportunities and of significant risks and ethical perils. For nanotechnology, this leads to a paradox. On the one hand, there is extensive attention to the risks to environment and health from nanotechnology (Arnall 2003; EC SANCO 2004). Simultaneously, nanotechnology is seen as an important problem solver for those very issues (Andersen and Rasmussen 2006). There are multiple reports and policy documents which point to the opportunities offered by nanotechnology to solve environmental problems and health issues, as well as other challenges, for example food supply (see: Nanoforum 2004; Royal Society 2004; Aitken et al. 2006; Elvin 2007; Friends of the Earth Germany 2007; Schmidt 2007). While hype and risk issues are much discussed in

\footnotetext{
1 The framework as presented is slightly modified from Langlois (2003, p. 360).

2 "Dynamic transaction costs" are the inter-firm coordination costs which arise when a firm does not have the capabilities it needs when it needs them (Langlois 1992, 2004). They are the costs of persuading or teaching actors with relational assets (suppliers or customers) what is necessary for a given innovation (Langlois 1992).
} 
sociological analysis of nanotechnology, they have received limited attention in innovation economic research and hence we know little of their economic implications.

\section{The Danish window chain}

The following two sections investigate empirically how nanotechnologies enter into the window chain in Denmark. A qualitative study is presented of the nanotechnology strategies and innovation activities of core actors in the Danish window chain market. The Danish window chain comprises those firms active in Denmark in the market for windows, as well as their suppliers and customers. While most of these firms are headquartered in Denmark, international firms are also involved. The focus is on the middle of the value chain-the producers of glass and windows. These firms link with relevant (nano-active) suppliers and with customers in wholesale and retail trades. Final customers (the users of windows) and overall trends in demand are addressed indirectly, drawing on evidence from interviewees in the supply chain. Table 1 lists the main companies in the middle parts of the Danish window chain of relevance for nanotechnology development, with eight of these companies (as indicated in the table) forming the basis of the current study. The analysis is based on interviews conducted in 2009 and 2010, and also web-based information, secondary data, a national survey, ${ }^{3}$ and earlier studies by the author on nanotechology, green nanotechnology and nano-enabled construction (see Andersen and Rasmussen 2006; Andersen and Molin 2007; Geiker and Andersen 2009; Andersen and Geiker 2009; Andersen 2010; Andersen et al. 2010).

In examining the window sector, emphasis is placed on investigating how a traditional economic sector with a generally low rate of innovation reacts to the emerging sciencebased nanotechnology wave. Vertical specialization in the window chain is characterized by a few very large advanced multinational glass manufacturers, many small mostly traditional glass processing and window producers, and a range of project-oriented construction companies. The Danish innovation system itself is an example of a small innovation system - with few large multinational enterprises, relatively small universities, and low level of R\&D-yet with a high overall innovative performance. This is not necessarily what the literature suggests would be an ideal environment for nanotechnology growth. What kind and extent of nanotechnology uptake can we expect in the Danish window chain?

There is generally a low-level deployment of nanotechnology in the broader construction sector (Gann 2003; Crisp/SPRU 2003; Bartos et al. 2004; Zhu et al. 2004; Fellenberg and Hoffschulz 2006; Luther and Zweck 2006; Andersen and Molin 2007; Geiker and Andersen 2009). However, there is quite a high number of nanotechnology applications in the Danish window chain. Start-ups, the major multinational companies, and-perhaps most surprisingly—small to medium sized incumbents all play important roles in the development and uptake of nanotechnology in the window chain. Generally, nanotechnology is playing a surprisingly important and rising role for Danish glass and window innovation. There are important fully commercial nano-enabled products plus a variety of development projects and emerging new nanotechnology applications. This is all

\footnotetext{
3 The analysis draws on findings from the report Green Nanotechnology in Nordic Construction-Ecoinnovation Strategies and Dynamics in Nordic Window Chains. See Andersen et al. (2010) for a further account of the methodology used and more detailed empirical analyses.
} 
Table 1 Core companies in the nanotechnology-enabled Danish window chain

\begin{tabular}{|c|c|c|c|}
\hline Company & $\begin{array}{l}\text { Corporate location } \\
\text { (and affiliation) }\end{array}$ & Key products & Year established \\
\hline $\begin{array}{l}\text { Fiberline } \\
\text { Composites* }\end{array}$ & Denmark & $\begin{array}{l}\text { Composite materials for } \\
\text { buildings and windmills }\end{array}$ & 1979 \\
\hline Dyrop & Denmark & Paint & 1928 \\
\hline Accoat & Denmark & Coatings & 1969 \\
\hline Superwood* & (VKR Group, Denmark) & $\begin{array}{l}\text { Wood preservation (nano- } \\
\text { enabled) }\end{array}$ & $\begin{array}{l}2002(\text { VKR since } \\
\text { 2006) }\end{array}$ \\
\hline Photocat* & Denmark & $\begin{array}{l}\text { Nano photo-catalytic } \\
\text { materials for glass and } \\
\text { floors }\end{array}$ & 2009 \\
\hline ScanGlass & $\begin{array}{l}\text { Denmark (affiliate of Saint- } \\
\text { Gobain Glass, France) }\end{array}$ & $\begin{array}{l}\text { Glass processing, } \\
\text { wholesale }\end{array}$ & $\begin{array}{l}1935 \text { (Saint-Gobain } \\
\text { since 1976) }\end{array}$ \\
\hline Pilkington Denmark* & $\begin{array}{l}\text { Denmark (affiliate of } \\
\text { Pilkington NSG Group, } \\
\text { Japan) }\end{array}$ & $\begin{array}{l}\text { Glass wholesale and } \\
\text { mirror processing }\end{array}$ & $\begin{array}{l}1978 \text { (NSG Group } \\
\text { since 2006) }\end{array}$ \\
\hline Sunarc Technology* & Denmark & $\begin{array}{l}\text { Sheet glass (nano- } \\
\text { enabled) for solar } \\
\text { collectors, PV-modules, } \\
\text { greenhouses }\end{array}$ & 2000 \\
\hline VELUX* & (VKR Group, Denmark) & $\begin{array}{l}\text { Roof windows and } \\
\text { skylights }\end{array}$ & 1941 \\
\hline $\begin{array}{l}\text { Dovista Group*-_ } \\
\text { VELFAC and } \\
\text { Rationel }\end{array}$ & (VKR Group, Denmark) & $\begin{array}{l}\text { Vertical windows and } \\
\text { doors }\end{array}$ & $\begin{array}{l}1954 \text { (Rationel) } \\
1961 \text { (VELFAC) } \\
2004 \text { (Dovista) }\end{array}$ \\
\hline PRO TEC Vinduer* & Denmark & Vertical windows & 1993 \\
\hline
\end{tabular}

Source Based on company webpages and interviews

* Companies of primary focus in the case

relatively unpublicized and represents a form of "silent innovation" in nanotechnology (a concept that is returned to later in the paper).

\section{Nano-innovation in the Danish window chain}

\subsection{The glass producers and distributors}

The large glass producers represent the major channel through which nanotechnology is introduced into the window chain. ${ }^{4}$ Since the 1970s, the national offices or subsidiaries of the multinational companies Pilkington and Saint Gobain have dominated the Danish and Nordic glass supply and distribution markets. There is no float glass production left in Denmark. A further 29 mainly small companies deal with glass processing or wholesale activities in Denmark.

\footnotetext{
4 This section draws on Andersen et al. 2010, including interviews with Pilkington Denmark and VELUX, and web pages, company reports and secondary materials. Emphasis is placed on market developments as reported by Pilkington Denmark.
} 
Modern high-value products in the window sector are made from processing the basic float glass by laminating, toughening and coating, as well as assembling the glass into insulating glass units (double or triple glazing). Over the past 30 years, product innovation in the glass itself has focused on meeting a widening range of functionalities. These include producing glass with improved performance in terms of thermal insulation, solar control (to reduce heat loss and regulate ventilation), security and safety, fire resistance, noise reduction, anti-reflection, self-cleaning, anti-scratching, and visual appearance. Nanoscience has been used over these three decades in the development and application of coatings to offer improved glass performance features, evolving through incremental trial and error long before the recent buzz associated with nanotechnology but accelerating with the advance of modern nanoscience in the $1990 \mathrm{~s}$. Today's coatings are multi-layer, up to 7 or more layers, to achieve multifunctional glass achieved either online (soft coatings) or offline (hard coatings). All modern flat glass coatings are based on nanotechnology.

The multinational glass companies have taken the lead in developing advanced nanocoatings. According to Pilkington Denmark, the competition in glass is intense and technology-oriented. Modern glass production is continuous, with large-scale mass production, and is highly capital intensive. Concentration in the sector is high. In 2004, the four largest global players-NSG (since 2006 including the large UK Pilkington Group), Saint Gobain Glass, Asahi and Guardian Industries-held a combined share of around $80 \%$ of the flat glass market in Europe. ${ }^{5}$ All the big glass players have extensive R\&D activities and a varied product portfolio in flat glass production directed at two major markets: the construction sector and the automotive/transport sector. Of the two, the construction sector is the largest market, taking about four-fifths for total glass output, but this sector is traditionally not innovative. The automotive/transport sector is more focused on innovation and is $R \& D$ intensive. Several of the parent glass companies have extensive activities in other (non-glass) parts of the construction sector and-relevant for nanotechnology development-in materials and chemicals. ${ }^{6}$

Pilkington spends around $£ 33$ million a year on $R \& D$, organized within their two business lines of building products and automotive products. Additionally, Pilkington cooperates with the R\&D labs of the parent Japanese NSG Group. Pilkington marketed the first self-cleaning glass in $2001 .^{7}$ This has garnered international recognition as one of the first commercially-available nano-consumer products. Within a year, PPG Industries, Cardinal Glass Industries and Saint Gobain also launched their self-cleaning glass products. Self-cleaning glass is now widely available in glass wholesalers' product portfolios, although it still awaits a major breakthrough in market demand.

Despite the publicity ("nano-fame") associated with its self-cleaning glass, Pilkington does not officially refer to it as an application of "nanotechnology". The term "nanotechnology" is generally avoided and instead they use the traditional term of "coatings". The company maintains a low profile related to nanotechnology, and there is only little

\footnotetext{
5 Source: http://europa.eu/rapid/pressReleasesAction.do?reference=IP/07/1781, 2007.

6 See also Pilkington (2009a).

7 Self-cleaning glass cleans itself through photocatalytic processes. The Pilkington Activ brand by Pilkington uses a $15 \mathrm{~nm}$ thick transparent coating of microcrystalline titanium dioxide. The coating is applied by chemical vapor deposition. Self-cleaning glass lowers maintenance requirements, reduces outside condensation (a rising problem in energy efficient houses), and saves detergents, water and energy use (Pilkington 2009b).
} 
reference to nanotechnology in their materials information on their web page. ${ }^{8}$ According to Pilkington Denmark, their low profile is due partly to the unsettled debate on nanotechnology risk issues and partly because of the considerable uncertainty as to what nanotechnology is and what it is not. Examples of products that over-exaggerated their nanotechnology performance attributes ("nano-fakes") have created negative reactions from customers. Pilkington currently sees no market advantage or profit opportunities in "nano-marketing" to emphasizing their product's nanotechnology characteristics. This "silent" attitude to nanotechnology is shared by most of the other big glass companies. The term nanotechnology receives little if any attention in webpages or company reports. The exception is PPG (the world's sixth largest glass producer), which markets itself as a nanotechnology company hence displaying a very different nanotechnology strategy from its other large competitors. ${ }^{9}$

According to Pilkington Denmark, self-cleaning glass has failed to attract a high level of market demand. The market for flat glass is driven very much by regulation, but there is a lack of regulation that would generate demand self-cleaning features. However, there is demand for other glass coating features. In particular, energy efficiency is a core and rising driver for glass innovation-and an area of substantial focus for policymakers and regulators over the last 20 years. Low emissivity and solar control glass are standard offerings in today's markets, achieved via soft nano-coatings. The potential market is huge since many countries primarily have one-layer standard glass in their current building stock. Hard coating technology is important in the area of solar technologies, where the market is booming due to concerns about climate change and energy costs.

Pilkington sees green demonstration houses as playing an important role for advancing radical product innovations in glass and windows. Radical innovations may be tested and funding is available for such projects. Pilkington Denmark sees the Nordic countries as being in the lead for taking up new advanced glass products and has therefore based its largest glass coating plant in Sweden. Yet, there are still barriers in marketing advanced glass innovations. Overall, the window and wider construction sector is not viewed as innovative and lacks new knowledge about glass. The construction sector is generally focused on production costs, while ongoing user costs are neglected. The builder, who typically will not live in the house, has little incentive for product innovation to reduce user costs. Since advanced nano-coated glass products have their advantages in the user phase, this is a major barrier for product innovation.

Another entrant in nano-enabled glass is Sunarc, a small Danish up-start company. ${ }^{10}$ Established in 2000, Sunarc specializes in the production of nano-structured anti-reflective surfaces on large glass sheets. The glass is aimed at niche applications within the markets for solar collectors, photovoltaic (PV) modules, and greenhouses and minimizes reflected light, hence improving light transmission. Sunarc uses a unique technology. Passing

\footnotetext{
${ }^{8}$ For Pilkington Activ, Pilkington says that: "Whilst the coating is nanometres thick it is really a development of thin film technology, rather than being a specific nanotechnology product. The name nanotechnology is usually applied to the scientific investigation or application of particles and/or structures which have sizes of less than one hundred nanometres. Particles or structures of this size can have unique properties compared with bulk materials. Pilkington Activ ${ }^{\mathrm{TM}}$ is based on a thin film of titanium dioxide rather than particles of titanium dioxide and the film is approximately 15 nanometres thick." http://www. pilkingtonselfcleaningglass.co.uk/faq/technical/(accessed February 2, 2011).

9 See, for example: PPG, "Nanotechnology Enabled Materials for Energy Conservation," presentation at EPA conference September 25, 2007 on Pollution Prevention through Nanotechnology, www.epa.gov/oppt/ nano/p2docs/session4_rardon.pdf.
}

${ }^{10}$ This section is mainly based on interviews with a management representative at Sunarc. . 
through several baths, the glass is subjected to a fully automated etching process. The resulting surface is a nano-porous structure of approximately $100 \mathrm{~nm}$ thicknesses on both sides of the glass. This glass transmits six to eight percent more sunlight, depending on the glass slope. Sunarc has a somewhat relaxed approach to nano-marketing. It does not actively market its products as nanotechnology products, but in company materials it does refer to itself as "a high-tech nano-based company."

After a slow start, Sunarc has seen a steady increase in sales and exports, especially in recent years with increased interest in new solar technologies. In 2006, the company moved to new production facilities and received Børsen's Gazelle award for being the second fastest growing company in Denmark. A new production line is planned, four new plants are being set up in other countries, and more are expected. The production facilities are not particularly expensive, so it is attractive to set up production where it is needed. Sunarc is considering moving into low emissivity (low-E) glass production for buildings to improve light transmittance, which represents a problem in current 3-layer insulating windows.

The capabilities underlying Sunarc's production are mainly tacit and rest with core employees. The critical elements lie in the fine adjustment of the production process, which is essential to achieve a uniform high product quality. The company has chosen not to patent its technology. Others have tried to copy what they are doing, including the larger glass companies. However, although laboratory-scale production is easy, scaling-up to commercial levels is difficult, and Sun-arc is still the leading full-scale global producer with this technology.

\subsection{The window producers}

The Danish window manufacturing industry is also an important entry point for nanotechnology in the window chain. This is surprising because the window industry is generally relatively small scale and is not popularly considered to be innovative. The Danish window industry consists of around 300 small producers, but is dominated by one large group, the VKR Holding Group. VKR has quite a high level of R\&D and is the locus of most of the nanotechnology activities in the Danish window industry.

VELUX is the dominant company within the VKR Group, with a well-known international brand and specializations in roof windows and skylights. ${ }^{11}$ Nanotechnology has long been of interest to VELUX because it plays an important role among a number of their suppliers and in the components of their products. VELUX has its own R\&D department, which is divided into two sections, one for the frame and one for glass. Both sections are involved in nanotechnology R\&D. They track developments elsewhere so that the company has the necessary capabilities to select the right products from their suppliers. For example, selecting glass features is a key competitive factor. Knowledge and insight about nanotechnology is especially important in the glass R\&D section: they maintain dialogue with the major glass producers about their nano-coatings and are well informed about all details of these.

Dovista, also part of VKR, is the holding group of the main two Danish producers of vertical windows, Velfac and Rationel. Dovista undertakes R\&D for these two affiliates. In the past, Dovista was not focused on nanotechnology and did not undertake targeted searches into nanotechnology innovations. However, interest is now growing. In 2009, Dovista began their first nanotechnology R\&D project, with a Danish university, aimed at

11 This section is based on interviews with managers at VELUX and Dovista. . 
reducing condensation problems of windows (which, as noted, is a major issue in increasingly energy efficient buildings). There is also cooperation between VELUX \& and Dovista: they draw heavily on each other's R\&D and engage in common product developments and marketing.

Over the last ten years VELUX's interest in nanotechnology has grown alongside the general societal interest about nanotechnology. Since 2006, VELUX has participated in the nanotechnology background group of Danish Standards, working on risk issues, characterization, metrology, and related topics. VELUX is one of only a handful of Danish companies who participate in such work. From 2005 through to 2009, the company also participated in the Danish "NanoPaint" collaborative nanotechnology R\&D project, which also involved paint, coating and chemical suppliers as well as Danish knowledge institutions. The project sought to develop nanotechnology surface coatings. VELUX was interested in more durable paint for wood as well as more environmentally friendly metal coatings, although the project had a limited outcome. According to VELUX, their main sources of knowhow are not research institutes but their varied major international suppliers who VELUX sees as being at the forefront of technological development, including for nanotechnology.

Nano-coated multifunctional glass is stocked in VELUX's product portfolio. Demand for high-energy performance is the core driver for glass product innovation over the last 20 years, especially during the last five to ten years. Low-E glass and solar control glass are standard in the markets VELUX sells to. Self-cleaning glass is also interesting to VELUX, since roof windows are difficult to clean. In some countries, it is offered as a standard window material, while in other countries it is an optional choice.

VELUX does not undertake explicit nano-marketing and there is no information about nanotechnology content or production processes in product descriptions. Nanotechnology is seen as an $R \& D$ input rather than a product criteria. However, risk aspects are an issue they are attentive to in their nanotechnology strategy development. They see two poles in the nanotechnology community. The first focuses on health and environmental issues, claiming that nanotechnology is risky. The second maintains that there are no problems to stop pushing ahead with these promising technologies. VELUX seeks a middle way between these poles, keeping track of developments related to nanotechnology risks.

The VKR Group has recently become engaged in nano-enabled product development for wood impregnation. ${ }^{12}$ VKR has long been looking for more environmentally-friendly wood preservation methods. In 2006, VKR bought Superwood, a Danish start-up company, which offers a nanotechnology-based and environmentally-friendly wood impregnation method using supercritical carbon dioxide (CO). ${ }^{13}$ The method is based on a 2001 patent. Superwood was started in 2002 as a buy out from FL Schmidth—a Danish-based global supplier to the cement and minerals industries. Superwood struggled with scaling up, and went bankrupt in 2003. Following VKR's purchase of the company in 2006, VELUX, Dovista and Superwood are jointly engaged in further development of Superwood's technology, targeted specifically to window products. The idea is to obtain durability due to anti-fungus treatment of the wood and a water repellent effect. The results are promising and they hope to start large-scale production of the Superwood frames soon. This product

\footnotetext{
12 This section is mainly based on interviews with managers at Superwood A/S and Dovista. .

13 The Superwood method protects the wood all the way into the kernel. This gives boards a substantially longer lifespan. In addition, this method enables the impregnation of wood species such as spruce that cannot be impregnated using traditional methods. The technique is environmentally-friendly since it does not use toxic chemicals.
} 
would be unique worldwide. In the meantime, since 2006, Superwood-treated timber is available for general consumer use in construction, with the market for such green products expanding rapidly. Superwood markets its products as green products rather than nanoproducts. There is a reference to nanotechnology on the company's web site, but it is not very visible.

The most radical recent product innovation in the Danish window chain is the development of composite window frames to improve energy efficiency. ${ }^{14}$ While glass has become much more energy efficient the last 20 years, the window frames have not. The frames act as thermal bridges, a problem that is little recognized by users and which has been receiving policy attention only lately. New more systemic policies (earlier policies were only directed at the glass) are creating incentives for innovations in frames. The first Danish composite product was developed by the small incumbent PRO TEC, with commercial success. Dovista has recently also engaged in developing similar products, with these applied so far in green demonstration houses. These green demonstration houses, built by many Danish municipalities, are seen as important sources of experimental product innovation. However, neither of the two composite products is nano-enabled. PRO TEC's composite supplier is Fiberline, but this company is not active in nanotechnology development and only possesses minor interests in nanotechnology.

Recently, the VKR Group has undertaken an interesting strategic change, shifting from focusing on developing windows to acting as developers of buildings, more specifically energy efficient buildings. They increasingly see and market themselves as "producers of light and fresh air" rather than producers of windows. VKR serves as a lead actor in several green demonstration house projects, engaging in systemic, smart eco-innovation at the building level. ${ }^{15} \mathrm{VKR}$ is set to demonstrate that it is possible to construct advanced green buildings with large window areas to address Danish energy regulations restricting the window surfaces. ${ }^{16}$ In so doing, they are replacing construction companies, taking on a new role as system integrators in the growing green building market.

\subsection{After-treatment producers}

A further nanotechnology entrant in the window chain is Photocat $\mathrm{A} / \mathrm{S},{ }^{17}$ a Danish start-up company. Photocat produces nano-structured materials and coatings with photocatalytic properties, e.g. self-cleaning functions. Photocat has a product directed at the glass market, ShineOn ${ }^{\circledR}$ Pro, which is an aftermarket treatment to make window glass self-cleaning. The company is a spin-out from SCF Technologies A/S, a dedicated Danish nanotechnology company that from 2003 also specialized in supercritical technology, similar to Superwood. ${ }^{18}$

SCF initially experimented with a range of applications for supercritical technology. $\mathrm{SCF}$ focused relatively quickly on bio-oil from organic waste, which is now the core focus

\footnotetext{
14 This section is mainly based on interviews with managers at Fiberline, PRO TEC, and Dovista.

15 This entails integrating windows and blinds with electronic systems, innovative building design with optimal utilization of daylight and natural ventilation, combined with artificial light (including nano-based LEDs).

16 The Danish Building code (from 1979) regulated the energy consumption of a house by specifying the maximum surface area for windows (15\%), as windows were considered heat losers compared to the rest of the building envelope.

17 This section is mainly based on interviews with managers at Photocat.

18 SCF is a spin-out from FL Smidth, a Danish construction company -similar to the company Superwood .
} 
of the company. In the advanced materials area, SCF focused on self-cleaning glass. For this product SCF initially relied on imported nano-materials from China, but after encountering technical challenges the company began work to design its own nanoparticles leading to the development of the patented ShineOn ${ }^{\circledR}$ product in 2005 . This work was not based on supercritical technology but rather on nanoscale photocatalysis. Sets of nanoparticles are configured using pear mill technology (in cooperation with a German supplier) and the wet grinding of materials at the micro- to nano-scales. The end product for applying the window self-cleaning glass coating consists of two fluids as well as a set of recommended spray containers and education to ensure correct handling. Additionally, working with a Swedish floor company, Välinge Innovation, in 2007, a new patented composite flooring material was developed (ActiFloor). Photocatalytic nanoparticles are integrated in the floor material matrix, the first of its kind. These floors are depolluting, improving the indoor climate (formaldehyde release is eliminated from the floor itself, while the floor also removes formaldehyde from other sources). With SCF seeking to focus on products other than self-cleaning materials, Photocat was spun-out in 2009, with plans to start industrial production of the floors in 2010. Meanwhile, ShineOn has been licensed by Photocat to wholesale companies in the UK and US, with moderate success. The users are professional glaziers and renovation companies. In Denmark marketing activities have been limited and no license partner has been found.

Photocat promotes itself as a clean-tech nano-based company. As the nano wave is not as hot as earlier, nano-branding is less important to the company. However, Photocat is the company with the most explicit nano-oriented marketing in the Danish window chain. Documentation and external validation are seen as important by Photocat, addressing both quality and health and risk issues related to nanoparticles. ${ }^{19}$

The following sections consider the empirical findings in the context of strategies for nanotechnology entry and the Model III mode of nanotechnology development.

\section{Strategies for nanotechnology entry: towards a taxonomy}

Nanotechnology is a generic and enabling technology which affects a very spectrum of companies in very different ways, most of which have been little analyzed to date. However, based on the evidence from the case studies of nanotechnology firms in the Danish window chain, a taxonomy is suggested which sheds light on important differences in firm strategies for nanotechnology. The taxonomy is based on three criteria: (1) the capabilities of the firm; (2) the firm's role in technology generation and application; and (3) the strategic importance of nanotechnology to the core business activities of the firm. There are nine types of firms in the taxonomy. In order to illustrate the taxonomy, examples from the Danish window chain are referred to.

The first three types of firms emerge out of the nanotechnology sector itself, namely: Category 1: the makers of instruments, equipment, facilities and software for nanotechnology production; Category 2: producers of generic nano-materials; and Category 3: producers of nano-services, e.g. specialized consultants who advise on aspects related to nanotechnology. Firms in these three categories enable other firms to develop and apply

\footnotetext{
19 The Danish Technological Institute conducted an independent test which verified ShineOn's selfcleaning properties, finding that they equaled the cleaning capacity of the well-known Pilkington and SaintGobain brands. All of Photocat's products have material data safety sheets prepared in cooperation with experts and in compliance with regulations.
} 
nanotechnology. Such firms have not in a visible or important way been involved in nanotechnology innovation in the Danish window chain, with the exception of the Photocat case where cooperation with the mill grinder supplier was important for the company's nanotechnology innovation.

The next set of firms is downstream, moving towards nanotechnology used. Category 4 comprises dedicated nanotechnology firms (such as Superwood, Sunarc and Photocat) where nanotechnology makes up a fundamental part of the firms capabilities and innovative activities and it is applied to develop innovative (nano)products. Category 5 consists of nanospecialized firms where nanotechnology forms a serious but not central part of their capabilities. The multinational glass producers are leading nanotechnology developers within the construction area, but they also possess other important capabilities and lines of business. Category 6 comprises nano-active firms, where nano R\&D play a modest but not very central role for their innovative activities and capability development. An example is VELUX, whose nanotechnology innovation is mainly centered on applying and integrating nanotechnology developed by others. Category 7 consists of nano-explorative firms, with no development activities in nanotechnology but with interest and some level of research into nanotechnology opportunities (as for Pro Tec and Velfac/Dovista). Category 8 encompasses nano-tacit users with no R\&D in nanotechnology themselves but applying nano-enabled products (e.g. many construction companies and architects). They may be more or less knowledgeable about the nano-content of their products. Finally, Category 9 contains what can be termed nano-shadow companies. Nanoscience forms part of their underlying technology base and is applied in niche products by others in the sector. However, companies in this category have limited or nil efforts themselves in developing or applying nanotechnology. These companies are typically relatively high tech and are potentially nano-dedicated companies. An example of such a firm is Fiberline.

\section{Model III nanotechnology development: reflections and insights}

It appears that nanotechnology follows an intermediate model of technology development as compared to that of ICT (dominated by the large firms) and biotechnology (dominated by small spin offs). As discussed earlier, it is suggested that there is a Model III nanotechnology evolution, where nanotechnology commercialization is driven significantly by small and medium sized firms based on their internal know how and with larger firms as key knowledge suppliers. Model III small and medium sized firms seem to be good at sensing new societal needs in the marketplace, which can form the germ for early nanotechnology commercialization processes.

\subsection{The distribution of nanotechnology capabilities in firm and market}

Nanotechnology has already affected the organization and operation of the window sector. Large companies play a central role, through the provision of nano-based coatings (by the large glass companies) and chemicals and metal materials. A small number of these large integrated organizations placed upstream have substantial nanotechnology capabilities which function as a source for firms further downstream. They are complemented by nanodedicated start-up companies who, in the Danish window case, have developed several promising new nano niche products.

This picture is consistent with Shapira et al. (2010) who suggest that both the large and the small firms play significant roles for nanotechnology development at the current stage. 
However, the Danish findings indicate that medium-size players in the Danish window industry (both in size and chain position) play a key role as integrators of a variety of nanotechnologies. Internal $R \& D$ combined with input from their large suppliers form the basis of their internal nano-capabilities. The recent observed strategic shift among midchain window producers from window to green building providers strengthens their roles as system integrators, indicating that they may become even more important carriers of nanotechnology commercialization in the future.

While there seems to be a distributed set of nano-capabilities in the window chain, this case study also highlights (although without detailed examination) the widespread disinterest and lack of awareness among many of the smaller and medium-sized companies who dominate the construction sector, as investigated more widely in (Andersen and Molin 2007). Even companies that are innovative in other domains (such as Fiberline) are not very engaged with nanotechnology.

\subsection{The systemic nature of the economic change}

At the technological level, there are as yet few signs of nano-enabled systemic innovations which require significant complementary innovations or new capabilities. An exception is soft-coated glass which requires special and quite delicate practices and capabilities among the processing customers. Since soft-coating is already a well-established technology, there are no immediate signs of innovation coordination needs caused by nanotechnology itself in the window chain. On the contrary, the nano-surface treatments, which are the most widespread nanotechnologies in the window chain, are valued by businesses because they can solve problems as an add-on, without interfering in existing products and production processes. Overall, the anticipated general purpose transformative effects of nanotechnology are not yet apparent, at least in the industry studied in this paper.

\subsection{Silent innovation and market development}

Clearly nano-commercialization is at an early and quite uneven stage of development. Some nano-enabled products have been available for a surprisingly long time (10 - 30 years). But most of the more interesting developments in the downstream part of the chain are of a relatively recent vintage.

The paper has pointed to the "silent" nature of much of the nanotechnology market at the current stage. There has been a marked shift in the marketing strategies of firms engaged in nanotechnology innovation, from being quite "loud" or outspoken around the turn of the millennium about their nano-related activities and products towards becoming increasingly "silent" the recent years. Generally, most of the firms engaged in nano innovation in the Danish window chain pursue a discreet if not secretive strategy towards nanotechnology. This seems to be the case for all types of firms. Although the nanodedicated startups are relatively most outspoken, even these firms hold back on overemphasizing nanotechnology features in the marketing.

These discreet strategies are largely due to the health and environmental risk issues that are associated with nanotechnology, but also reflect general uncertainty about the value of nanotechnology terms and features in the market. Outside of a few core producers and users, nanotechnology is not well-defined or understood. Nanotechnology innovation is thus often silent in the sense of it not being communicated to the market. Additionally, this is also internally related to $\mathrm{R} \& \mathrm{D}$ processes. Although there has been an evolution of nanotechnology from trial and error testing to more formal modeling, much 
nanotechnology is insufficiently codified. The nano-prefix is used flexibly, as and when it advantages firms. The lack of codification of nanotechnology partly explains the silent innovation in nanotechnology. But there is also deliberate strategizing, with firms knowing that they are applying nanotechnology to their processes and products yet choosing not to publicize this in the market. Overall, there is much nanotechnology applied in the window chain that is little communicated and not widely known. This trend reflects what might be viewed as a downward nano-wave, where nanotechnology faces reputation problems to such an extent that the "nano" hardly functions as a selection device on the market. Firms hesitate to enter the nano-market because of these reputation problems.

The firms seriously engaged in nanotechnology innovation at the current early stage not only have to build up nanotechnology capabilities but also a nanotechnology business model. Part of this business model involves market-making-as firms have to invest in building nano-specific market-supporting institutions such as standards, documentation and communication about quality and risk issues. Another part of this business model involves considering how to market nano activities and address social needs. The firms successful in nanotechnology seem to be those mastering and carefully implementing these aspects of nanotechnology management and strategizing. Small and medium sized companies seem to have an advantage here, with small nano-dedicated firms taking much of the early risk in nano marketing and thereby the establishment of the nano market.

Nanotechnology appears to be strongly nested in sustainability issues. The green wave in the economy influences the uptake of nanotechnology in the window chain considerably. There is growing awareness of climate change and energy issues, including in the construction sector. But a proposition could be that nanotechnology is being positioned strongly as a solution to environmental and energy problems because of nanotechnology's extraordinary need to outweigh possible nano-risks with societal benefits. Particularly in the embryonic stage, when there is uncertainty as to effects, there is a need to legitimize a new technology.

It seems that the hype-nature of nanotechnology influences its economic development in mixed ways. The commercialization process is slowed down as silence about nanotechnology hampers the selection process. The long-term implications of silent nanotechnology innovation are uncertain. It may be that the nano-market will not greatly evolve, as technology remains an R\&D "black-box" input which firms see no need to market. Or it could represent an intermediate stage that will evolve into stronger selection mechanisms as the nano market matures. On the other hand, the careful nano strategizing that has evolved, noticeably the serious early attention to risk issues and to documentation, may in the long run turn out to be a viable strategy. It may lead to the creation of informed and well-functioning markets for the new technology, which may in later stages may speed up the commercialization process.

\section{Conclusions}

This paper has posited the need to put greater emphasis on the market formation side rather than the technology generation side in explaining early technology evolution. A Model III mode of nanotechnology evolution has been proposed based on an evolutionary capabilities perspective. This model suggests that nanotechnology commercialization is driven mainly by small and medium sized firms based on their internal knowhow, with large firms as important suppliers of knowledge. These smaller firms seem to be adept at addressing social needs and building nano-markets, the latter being a key factor in the nano- 
commercialization process. A taxonomy consisting of nine different types of enterprises engaged in nano entry has been proposed, illustrating the very diverse impacts of nanotechnology on firms.

The paper points to a marked shift in market formation, where the "loud" phase of nanotechnology of earlier years has subsided into the current "silent" period. Small nanodedicated firms are those who bear the main risk of nano marketing, being relatively less silent. It seems that the hype features of nanotechnology have been important in not only shaping the institutional setting around nanotechnology but also in directly influencing its market formation, with the close nesting of nanotechnology with environmental issues. The silent nature means that "nano" has limited value as a selection criterion on the market, slowing down the commercialization process currently. However, findings from the Danish window sector do indicate a rise in nano-commercialization as more downstream applications appear in recent years. However, there is little broader attention and awareness to this form of nanotechnology commercialization and a lack of recognition of the significant nano-enabled eco-innovations that are occurring in the chain.

Acknowledgments The analysis presented in the paper is based on the Danish part of the project "Green Nanotechnology in Nordic Construction-Eco-innovation strategies and Dynamics in Nordic Window Chains" (2007-2010) sponsored by the Nordic Innovation Centre. The author would like to thank two anonymous reviewers for valuable inputs.

\section{References}

Aitken, R. J., Chaudry, M. Q., Boxall, A. B. A., \& Hull, M. (2006). Manufacture and use of nanomaterials: Current status in the UK and global trends. Occupational Medicine, 56, 300-306.

Andersen, M. M. (2010). Cuando la alta technologia se encountra con la baja tecnología: dinámicas de ecoinnovacíon y estrategia corporative en el sector de la construction. Ekonomiaz, 75(3), 112-139.

Andersen, M. M., \& Geiker, M. R. (2009). Nanotechnologies for climate friendly construction-key issues and challenges. In Z. Bittnar, P. Zeman, \& P. J. M. Bartos (Eds.), Nanotechnology in construction. Berlin, Heidelberg: Springer.

Andersen, M.M., \& Molin, M. (2007). NanoByg: A survey of nanoinnovation in Danish construction. RisoeR-1234(EN) Ris $\emptyset$ National laboratory, Roskilde. http://www.risoe.dk/rispubl/reports/ris-r-1602.pdf.

Andersen, M. M., \& Rasmussen, B. (2006). Environmental opportunities and risks from nanotechnology. Risoe-R-1550-EN Ris $\emptyset$ National Laboratory, Roskilde, http://www.risoe.dk/-rispubl/-reports/risr-1550.pdf.

Andersen, M. M., Sanden, B., \& Palmberg, C. (2010). Green nanotechnology in nordic constructioneco-innovation strategies and dynamics in nordic window chains. Electronic report, the Nordic Innovation Centre. http://orbit.dtu.dk/getResource?recordId=267735\&objectId=1\&versionId=1.

Arnall, A. H. (2003). Future technologies, today's choices: Nanotechnology, artificial intelligence and robotics-a technical, political and institutional map of emerging technologies. London: Greenpeace Environmental Trust. http://www.greenpeace.org.uk/MultimediaFiles/Live/FullReport-/5886.pdf.

Bartos, P. J. M., Hughes, J. J., Trtik, P., \& Zhu, W. (Eds.). (2004). Nanotechnology in construction. Cambridge, UK: Royal Society of Chemistry.

Bonaccorsi, A., \& Thoma, G. (2008). Institutional complementarity and inventive performance in nano science and technology. Research Policy, 36(6), 813-831.

Bozeman, B., Larédo, P., \& Mangematin, V. (2007). Understanding the emergence and deployment of nano S\&T. Research Policy, 36(6), 807-812.

CRISP/SPRU. (2003). The Emperor's new coating: New dimensions for the built environment: The nanotechnology revolution. London: CRISP. www.crisp-uk.org.uk/REPORTS/-NanoReport-Final-270103.pdf.

Delemarle, A., Kahane B., Villard L., \& Larédo P. (2009). Production in nanotechnologies: A flat world with many hills and mountains. Nanotechnology Law and Business, Spring, 103-122.

EC SANCO. (2004). Nanotechnologies: A preliminary risks analysis. Brussels: European Commission.

Elvin, E. (2007). Nanotechnology for green buildings. Indianapolis, IN: Green Technology Forum. (www.greentechforum.net). 
Fellenberg, R., \& Hoffschulz, H. (2006). Nanotechnologie und Bauwessen (Nanotecture). Düsseldorf: VDI Technologiezentrum.

Friends of the Earth Germany-BUND. (2007). For the responsible management of nanotechnology. http://www.bund.net/lab/reddot2/pdf/bundposition_nano_03_07.pdf.

Gann, D. (2003). A review of nanotechnology and its potential applications for construction. Brighton, UK: SPRU/CRISP.

Geiker, M. R., \& Andersen, M. M. (2009). Nanotechnologies for sustainable construction. In J. Khatib (Ed.), Sustainability of construction materials. Cambridge, UK: Woodhead Publishing Ltd.

Islam, N., \& Miyazaki, K. (2010). An empirical analysis of nanotechnology research domains. Technovation, 30, 229-237.

Langlois, R. N. (1992). Transaction cost economics in real time. Industrial and Corporate Change, 1, 99-127.

Langlois, R. N. (2002). Chandler in a larger frame: Markets, transaction costs, and organizational form in history. Enterprise and Society, 5(3), 355-375.

Langlois, R. N. (2003). The vanishing hand. Industrial and Corporate Change, 12, 351-385.

Langlois, R. N., \& Robertson, P. L. (1995). Firms, markets and economic change: A dynamic theory of business institutions. London: Routledge.

Laredo, P., Delemarle, A., \& Kahane, B. (2010). Dynamics of nanosciences and technologies: Policy implications. Paper presented at the Transatlantic workshop on nanotechnology innovation and policy, March 24-26, Atlanta, Georgia USA.

Luther, W., \& Zweck, A. (2006). Anwendungen der Nanotechnologie in Architektur und Bauwesen. Düsseldorf: VDI Technologiezentrum.

Lux Research. (2007). The Nanotechnology report 2006: Investment overview and market research for nanotechnology. New York, NY.

Mangematin, V., \& Rieu, C. (2009). The determinants of science-based clusters growth: The case of nanotechnology. Mimeo: GEM.

Mowery, D. (2010). Nanotechnology and the U.S. national innovation system: Continuity and Change. Paper presented at the Transatlantic workshop on nanotechnology innovation and policy, March 24-26, Atlanta, GA, USA.

Nanoforum. (2004). Benefits, risks, ethical, legal and social aspects of nanotechnology. Nanoforum report. http://www.nanoforum.org.

NSET. (2009). The national nanotechnology initiative: Research and development leading to a revolution in technology and industry, supplement to President's 2010 Budget. Washington, DC. http://www.nano. gov/NNI_2010_budget_supplement.pdf.

Penrose, E. G. (1959). The theory of the growth of the firm. New York: Wiley.

Pilkington. (2009a). Pilkington and the flat glass industry 2009. UK: Pilkington.

Pilkington. (2009b). Pilkington Glasfakta (catalogue). Selvrengørende glas. http://www.pilkington.com/ europe/denmark/danish/building+products/glasfakta+2009.htm.

Richardson, G. B. (1972). The organisation of industry. The Economic Journal, 82, 883-896.

Rothaermel, F. T., \& Thursby, M. (2007). The nanotechnology versus the biotech revolution: Sources of productivity in incumbent firm research. Research Policy, 36(6), 832-849.

Royal Society. (2004) Nanoscience and nanotechnologies: Opportunities and uncertainties. The Royal Society \& The Royal Academy of Engineering. http://www.nanotec.org.uk/finalReport.htm.

Schmidt, K. F. (2007). Green nanotechnology. Washington, DC: Woodrow Wilson International Center for Scholars-Project on Emerging Nanotechnologies. http://www.nanotechproject.org/process/assets/files/2701/187_greennano_pen8.pdf.

Shapira, P., \& Youtie, J. (2008). Emergence of nanodistricts in the United States: Path dependency or new opportunities. Economic Development Quarterly, 22(3), 187-199.

Shapira, P., Youtie, J., \& Kay, L. (2010). National innovation system dynamics and the globalization of nanotechnology innovation. Paper presented at the Transatlantic workshop on nanotechnology innovation and policy, March 24-26, Atlanta, GA, USA.

Tushman, M. L., \& Anderson, P. (1986). Technological discontinuities and organizational environments. Administrative and Science Quarterly, 31(3), 439-465.

Utterback, J. M., \& Abernathy, W. J. (1975). A dynamic model of process and product innovation. Omega, 3(6), 639-656.

Youtie, J., Iacopetta, M., \& Graham, S. (2007). Assessing the nature of nanotechnology: Can we uncover an emerging general purpose technology? Journal of Technology Transfer, 32(6), 123-130.

Zhu, W., Bartos, P., \& Porro, A. (2004). Application of nanotechnology in construction: Summary of a stateof-the-art report. Materials and Structures, 37, 649-658. 